\title{
QoS Menggunakan Metode HTB di Linux
}

\author{
Salman Suleman ${ }^{1}$ Frangky Tupamahu ${ }^{2}$ Idham Latief $^{3}$ \\ Program Studi D3 Teknik Informatika, Politeknik Gorontalo, 60111 \\ email : salman@poligon.ac.id, frangkytupamahu@poligon.ac.id, idhamlatief@gmail.com
}

\begin{abstract}
Internet saat ini menjadi kebutuhan yang penting bagi kita manusia. Akan Tetapi kemudahan akses internet tidak di iringi dengan meningkatnya jumlah atau besaran kapasitas bandwidth yang ada, sehingga dengan adanya metode HTB dapat membantu untuk mengelola bandwidth secara merata sesuai dengan kebutuhan client. Perkembangan Internet memunculkan permasalahan khususnya pada sisi pengelolaan bandwidth. Linux sebagai sistem operasi yang bersifat terbuka, menawarkan berbagai metode untuk membantu proses pengelolaan bandwidth, salah satunya dengan menggunakan metode Hierarchical Token Bucket (HTB) yang menjamin para pengguna jaringan mendapatkan bandwidth sesuai yang telah ditentukan. HTB memungkinkan client memperoleh bandwidth minimum yang disediakan. Penelitian ini dilakukan dengan mengumpulkan data dari berbagai sumber yang terkait, kemudian melakukan percobaan dengan mengimplementasikan HTB dengan menambahkan program aplikasi untuk membantu administrator mengelola dan mengatur alokasi bandwidth tiap client. Serta menjadikan bandwith dapat dibagi secara merata serta kualitas koneksi jaringan lebih stabil.
\end{abstract}

Kata kunci - Internet, Bandwidth, Hierarchical Token Bucket (HTB), Linux

\section{PENDAHULUAN}

Semakin berkembangnya dunia teknologi dan meningkatnya para pengguna internet di berbagai kalangan masyarakat, internet menjadi sebuah kebutuhan yang sangat penting manusia, mahalnya biaya sewa bandwidth yang diberikan ISP (internet service provider) membuat mayoritas masyarakat tidak berlangganan internet. Terlebih lagi belum adanya kesadaran masyarakat pentingnya dunia teknologi informasi di masa yang akan datang.

Adanya metode HTB (Hierarchy Token Bucket) dapat membantu untuk megelola bandwidth secara merata sesuai dengan kebutuhan client masing-masing. Untuk mengatasinya dibutuhkan sebuah metode yang mampu membantu proses pengelolaan bandwidth dengan baik. HTB yang digunakan karena suatu metode yang lebih baru dan sederhana dari $C B Q$ (Class Based Queueing) dan metode lainya diklaim mampu melakukan pembagian trafik pada tiap level maupun klasifikasi, sehingga bandwidth yang tidak dipakai oleh level yang tinggi dapat digunakan atau dipinjam oleh level yang lebih rendah serta lebih akurat dalam pembagian trafik.

Metode ini dipakai karena metode $H T B$ merupakan metode terbaru dan lebih akurat dan lebih sederhana disbanding metode metode sebelumnya, sebagai sistem operasi yang bersifat terbuka, menawarkan berbagai metode untuk membantu proses pengelolaan bandwidth, salah satunya menggunakan metode Hierarchical Token Bucket $(H T B)$ yang menjamin para pengguna jaringan mendapatkan bandwidth sesuai yang telah ditentukan misalnya memungkinkan client memperoleh bandwidth minimum yang disediakan. Selain itu sistem operasi ini dapat berjalan baik di PC yang menggunakan sistem operasi tersebut.

\section{LANDASAN TEORI}

\subsection{Quality of Service}

QoS (Quality of Service) adalah sebuah mekanisme layanan standar mutu dari sebuah aplikasi/produk, QoS didalam jaringan komputer digunakan untuk mengukur tingkat kualitas koneksi jaringan. Ada beberapa metode untuk mengukur kualitas koneksi seperti konsumsi bandwidth oleh user,ketersediaan koneksi dan lain lain. (athailah., : 95)

QoS (Quality of Service) merupakan sekumpulan teknik dan mekasnisme yang menjamin performasi dari jaringan komputer (terutamanya di internet) di dalam penyediaan layanan kepada aplikasi- aplikasi di dalam jaringan komputer. QoS (Quality of Service) dilihat dan diukur dari sudut pandang penyedia dilakukan dari sudut layanan. .(Pratama,I,p,a,eka., 2014 : 547,548)

\subsection{Bandwidth}

Bandwidth adalah suatu perhitungan konsumsi data yang tersedia pada suatu telekomunikasi. Dihitung dalam satuan bits per second (bit per detik). Bandwidth adalah luas atau lebar cakupan frekuensi yang digunakan oleh sinyal dalam medium transmisi. Dalam kerangka ini, Bandwidth dapat diartikan sebagai perbedaan antara komponen sinyal frekuensi tinggi dan sinyal frekuensi rendah. frekuensi sinyal diukur dalam satuan Hertz. sinyal suara tipikal mempunyai Bandwidth sekitar $3 \mathrm{kHz}$, analog TV broadcast (TV) mempunyai Bandwidth sekitar $6 \mathrm{MHz}$. Bandwidth diartikan juga sebagai takaran jarak frekuensi. 


\subsection{Managemen bandwidth}

Management bandwidth jika diartikan kedalam bahasa Indonesia adalah mengatur bandwidth .

Bandwidth management system (BMS) adalah sebuah metode yang diterapkan untuk mengatur besarnya bandwidth yang akan digunakan oleh masing-masing user sehingga penggunaan bandwidth akan terdistribusi secara merata. (Athailah.,2013 : 94)

\subsection{Hierarchical Token Bucket (HTB)}

HTB (Hirarchy Token Bucket) merupakan salah satu teknik antrian yang memiliki tujuan untuk menerapkan link sharing. Dalam konsep link sharing, jika suatu kelas meminta kurang dari jumlah service yang telah ditetapkan untuknya, sisa bandwidth akan di distribusikan ke kelaskelas lain yang meminta service. HTB menggunakan $T B F$ sebagai estimator yang sangat mudah diimplementasikan. Estimator ini hanya menggunakan rate, sebagai akibatnya seorang administrator hanya perlu mengatur rate yang akan di berikan ke suatu Kelas. (Prayoga ,Sukmajati.,2013:23)

\section{METEDOLOGI PENELITIAN}

Pada bagian ini menjelaskan mengenai gambaran umum pada Sistem manajemen bandwidth yang di akan diimplementasikan.

\subsection{Analisa Sistem Jaringan} ada

Berikut adalah model atau topologi jaringan yang sudah

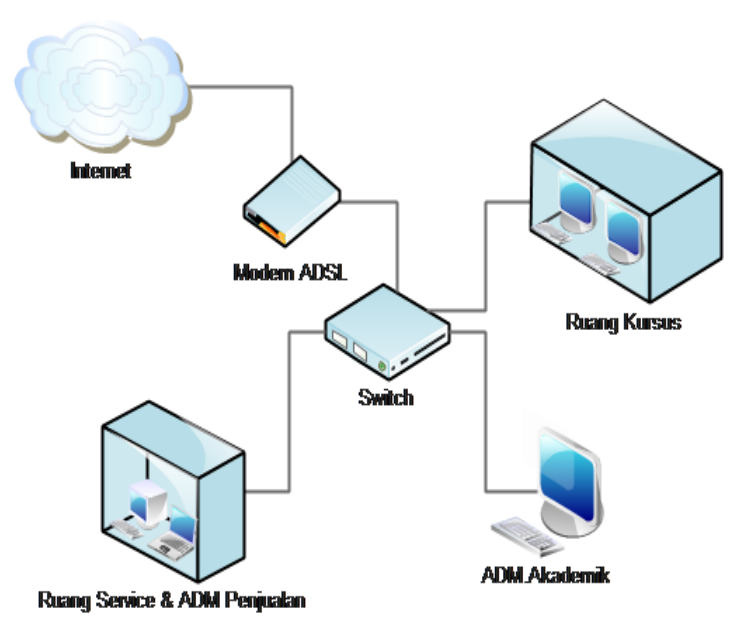

Gambar 3.1 Topologi existing

Seperti Pada gambar 3.1 terlihat bahwa topologi jaringan menggunakan topologi star sederhana dimana modem berfungsi sebagai gateway dan langsung terhubung secara fisik dengan switch dan didistribusi ke masing -masing ruangan seperti Ruang kursus, Administrasi Penjualan, Ruang service dan juga Administrasi akademik tanpa ada router yang mengatur arus lalu lintas data dan pemakaian bandwith sehingga bandwidth menjadi tidak effisien dan juga komunikasi data berpotensi menjadi lambat.

\subsection{Perancangan Sistem Jaringan}

Perancangan sistem jaringan merupakan tahap pembuatan rancangan jaringan, dalam penelitian ini menggunakan rancangan seperti Gambar 3.2.

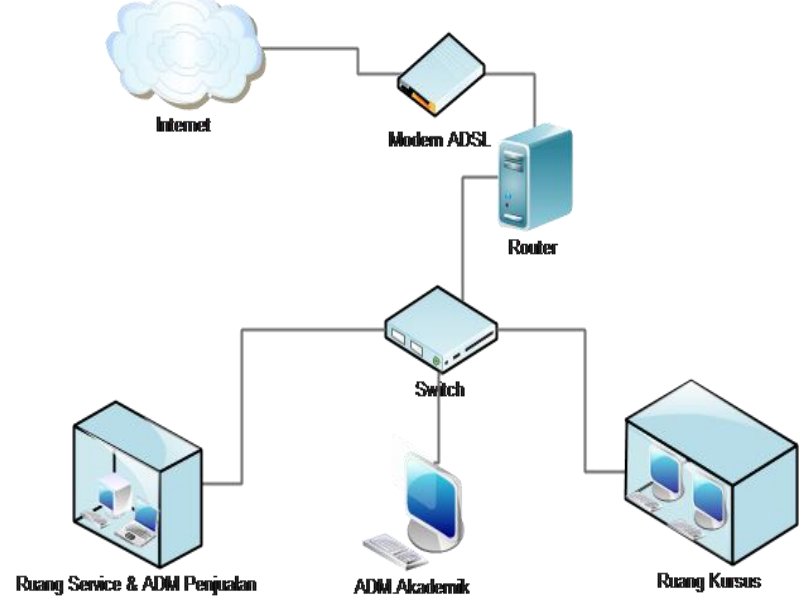

Gambar 3.2 Perancangan sistem jaringan

Pada gambar 3.2 merupakan model rancangan topologi yang akan digunakan, terdapat sebuah router menggunakan sistem operasi Linux Debian yang tehubung langsung dengan modem dan juga terhubung dengan beberapa client menggunakan media perantara switch dimana masingmasing ruangan tersebut memiliki kurang lebih untuk ruang kursus 10 client dan ruang service dan administrasi penjualan 4 sampai 5 client dan juga ruang administrasi akademik sebanyak 5 client sehingga total 20 client disini router berperan sangat penting pada saat pembagian masingmasing kapasitas bandwidth disetiap ruangan.

\subsection{Rancangan Manajemen Bandwidth}

Manajemen bandwidth ini akan membatasi penggunaan bandwidth jaringan Internet, manajemen dilakukan untuk membagi rata bandwidth per-client agar tidak tejadi congestion, jika sebuah jaringan Internet belum menerapkan manajemen bandwidth maka salah satu client menggunakan bandwidth secara penuh, client-client setelahnya akan mengalami antrian permintaan paket data dan mendapatkan bandwidth ketika permintaan paket data dari client 1 terpenuhi. Hal ini dapat mengganggu client-client lain dan mengganggu kinerja dari jaringan internet itu tersebut.

Berdasarkan Gambar 3.2 maka router akan mendapatkan bandwidth sebesar 1 Mbps dari ISP (Internet 
Service Provider) yang ada, sehingga dibuatlah sebuah rancangan management bandwidth dimana setiap client dari masing-masing ruangan akan memiliki kapasitas bandwidth sendiri ketika browsing dan download/upload, client pada masing ruangan itu memiliki $512 \mathrm{kbps}$ untuk ruang service dan administrasi penjualan jaringan, ruang kursus $256 \mathrm{kbps}$ serta untuk ruang administrasi akademik $256 \mathrm{kbps}$, setiap client memiliki aturan yang sama dalam satu ruangan sehingga tidak terjadi gangguan antara client tetapi dapat meminjam bandwidth jika salah satu client tidak aktif.

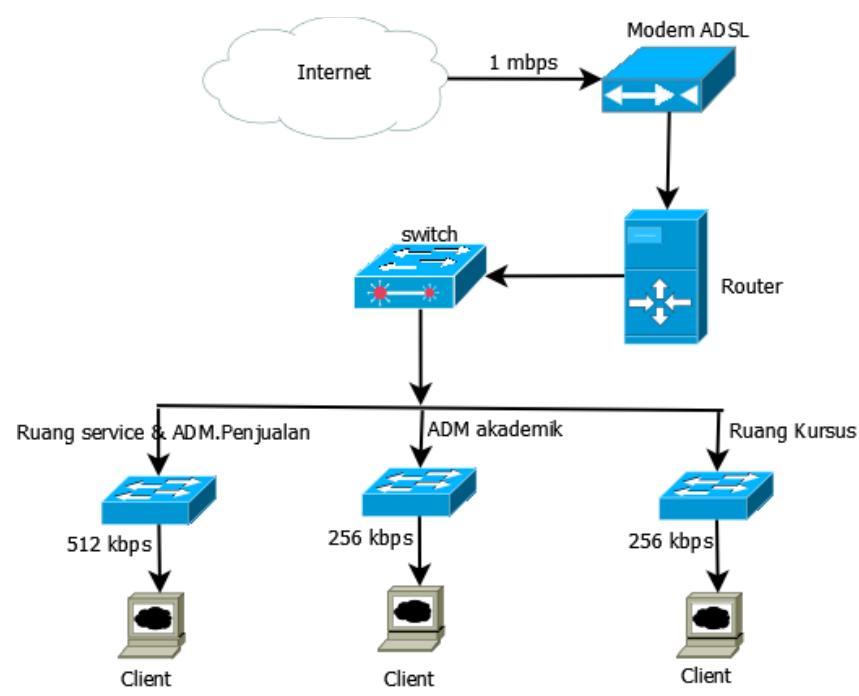

Gambar 3.2. Rancangan management bandwidth

\section{HASIL DAN PEMBAHASAN}

\subsection{Hasil}

Ketika client akan mengakses internet harus memasukan username dan password yang sudah di daftarkan di server. Seperti pada gambar 4.1

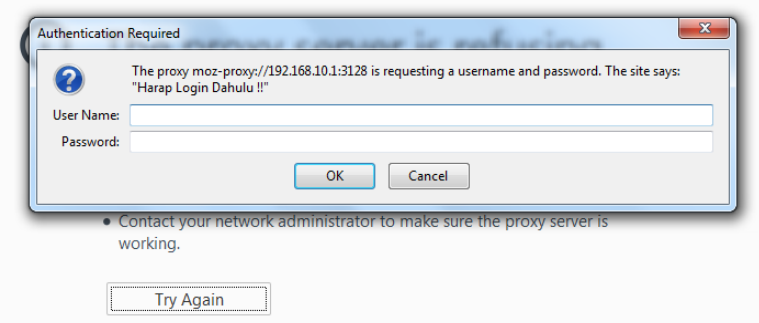

Gambar 4.1 request username dan password

Seperti yang di tunjukan pada gambar 4.41 bahwa client telah melakukan login dan berhasil masuk maka akan lansung bisa melakukan browsing seperti pada gambar 4.2
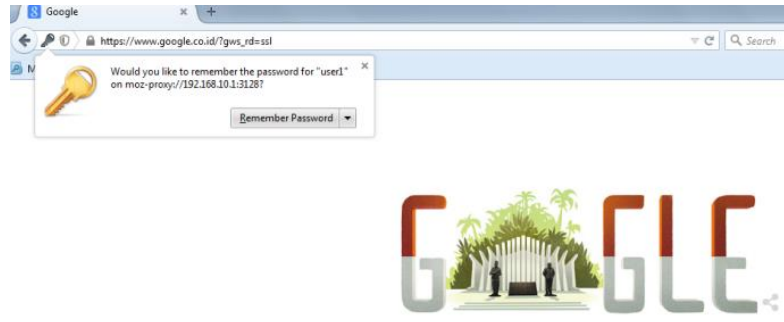

Gambar 4.2 client berhasil login

Jika client mencoba melakukan akses internet tanpa memasukan username dan password terlebih dahulu maka secara otomatis client tidak mengakses internet dan tidak di ijinkan oleh router untuk melakukan browsing, seperti yang di tunjukan pada gambar 4.3.

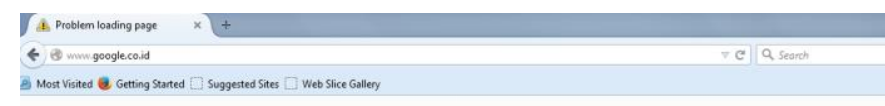

(i) The proxy server is refusing connections

Firefox is configured to use a proxy server that is refusing connections

- Check the proxy settings to make sure that they are correct. - Contact your network administrator to make sure the proxy sever is
working.

Tragain

Gambar 4.3 client tidak berhasil login

Setelah berhasil melakukan browsing maka langkah selanjutnya yaitu melakukan monitoring bandwidth yang terpakai dengan memanfaatkan $H T B$ yang telah di buat dengan pengujian via speedtest.net.

1. Pengujian bandwidth Client ketika belum di limit, seperti pada gambar 4.4

\begin{tabular}{|c|c|}
\hline$\stackrel{P}{\rightarrow} \stackrel{P I N G}{59}$ & $\downarrow \begin{array}{l}\text { DOWNLOAD SPEED } 0 \\
0.98_{\text {Mbps }}\end{array}\left(\begin{array}{l}\text { UPLOAD SPEED } \\
0.97_{\text {Mbps }}\end{array}\right.$ \\
\hline & SHARETHIS RESULT \\
\hline
\end{tabular}

Gambar 4.4 client belum di limit

Keterangan gambar 4.4: - Maksimal download $=980 \mathrm{Kbps}$ - Maksimal Upload $=970 \mathrm{Kbps}$

2. Pengujian bandwidth Client dari ruang service dengan limit download 512 Kbps. Seperti pada gambar 4.5. 


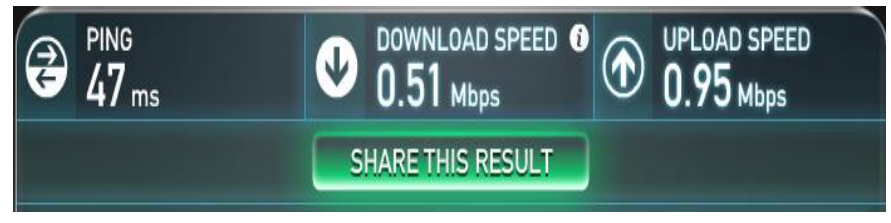

Gambar 4.5 client dengan di limit 512 Kbps

Keterangan gambar 4.5: $\quad$ - Maksimal download $=510 \mathrm{Kbps}$ - Maksimal Upload = 950 Kbps

3. Pengujian bandwidth Client dari ruang akademik dengan limit download 256 Kbps. Seperti pada gambar 4.6

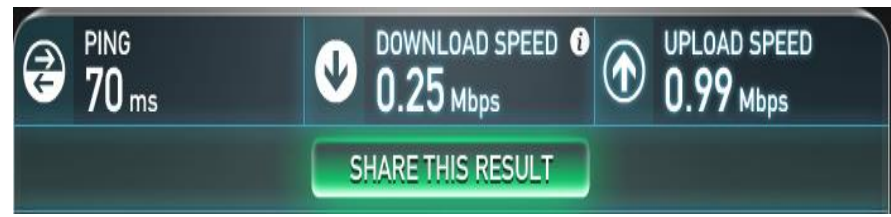

Gambar 4.6 client dengan di limit 256 Kbps

Keterangan gambar 4.6: - Maksimal download $=250 \mathrm{Kbps}$ - Maksimal Upload = $990 \mathrm{Kbps}$

4. Pengujian bandwidth Client dari ruang kursus dengan limit download 256 Kbps. Seperti pada gambar 4.7

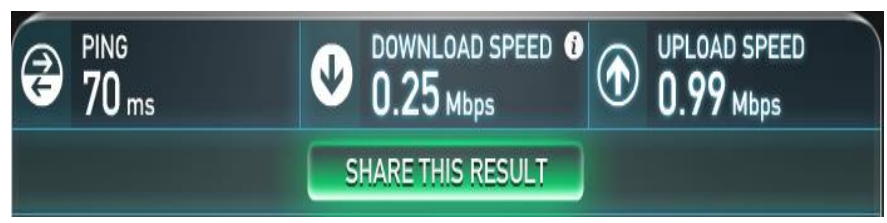

Gambar 4.7 client dengan di limit 256 Kbps

Keterangan gambar 4.7: - Maksimal download $=250 \mathrm{Kbps}$ - Maksimal Upload $=990 \mathrm{Kbps}$

Setelah melakukan pengujian client maka paket $H T B$ yang digunakan itu sudah berhasil membagi bandwidth yang ada sesuai yang di harapkan sesuai dengan setiap ruangan yag telah ditentukan. Jika ketika ketiga ruangan terpakai dan semua client di jalankan maka hasil dari monitoring lewat router dan kecepatan akses internet yang di dapat oleh client ketika semua ruangan melakukan browser secara bersamaan. Monitoring dari server seperti pada gambar 4.48

$\begin{array}{lrrrr}\text { mallcom } & 7.98 & 5 & 1024 & 1024 \\ \text { ruangakademik } & 6.82 & 4 & 38 & 256 \\ \text { ruangservice } & 0.58 & 0 & 64 & 512 \\ \text { ruangkursus } & 0.58 & 1 & 38 & 256 \\ \text { DEFAULT_ } & 0.11 & 0 & 8 & 8\end{array}$

Gambar 4.48 Monitoring server

Kecepatan maksimal setiap client dari ruang kursus ketika semua ruangan terpakai dan melakukan akses internet secara bersamaan. Seperti yang ditunjukan pada gambar 4.49

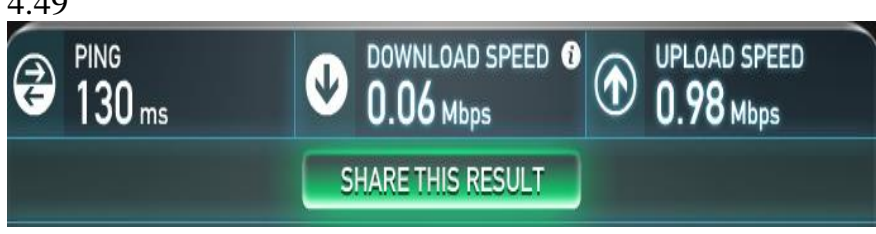

Gambar 4.49 kecepatan maksimal client

Keterangan gambar 4.49: - Maksimal download $=60 \mathrm{Kbps}$ - Maksimal Upload $=980 \mathrm{Kbps}$

\section{KESIMPULAN}

\subsection{Kesimpulan}

1. Manajemen Bandwidth yang di lakukan dengan metode HTB (Hierarchical Token Bucket) yang di terapkan pada sistem yang sudah di buat sehingga client mendapatkan bandwidth sesuai dengan kebutuhan dalam penggunaan akses internet serta dapat mengatasi masalah terutama pada lambatnya akses internet ketika melakukan browsing.

2. Autentikasi proxy berguna untuk melakukan pengawasan dan penyaringan maka user dipaksa harus memasukkan username dan password. Karena menggukan NCSA maka menjadi manual proxy, Bila username dan password tersebut valid dan terdaftar pada squid maka user tersebut diijinkan terkoneksi ke internet.

\subsection{Saran}

Untuk mengembangkan aplikasi ini selanjutnya.

Aplikasi ini masih dapat dikembangkan konten-konten yang ada dengan jenis-jenis mata pelajaran yang dapat disesuaikan

\section{DAFTAR PUSTAKA}

Athailah., 2013. "Mikrotik untuk pemula", Mediakita.

Hertzog ,R and Mas,R.,2013 “The Debian Administrator's Handbook".

Jusak,2013. "teknologi komunikasi data modern" Yogyakarta : Andi

Prayoga,Sukmajati.,2013. “Jurnal Teknik Komputer Unikom Komputika Volume2"

Pratama,I putu agus eka., 2014. "handbook jaringan komputer", Informatika.

Siyamta,2013. "sistem operasi" Malang : Kementerian Pendidikan \& Kebudayaan

Wijaya Indra,Alfon.,2012. "Jurnal Teknik Informatika Udinus" 